ISSN: 2576-2141

\title{
Multiple Cultures - One Process: Undertaking A Cross Cultural Grounded Theory Study
}

\author{
Shoba Nayar ${ }^{1}$ \\ AUT University, Auckland, New Zealand \\ Valerie Wright St.Clair \\ AUT University, Auckland, New Zealand
}

\begin{abstract}
Increasingly researchers are interested in the nexus of older adults, migration and health. Grounded theory is an ideal methodology to use in qualitative studies seeking to better understand the processes surrounding immigrants' resettlement and how they maintain their wellbeing. To date, grounded theory methods have been employed in New Zealand research with older Asian immigrants; however, such research has only involved one ethnic group per study. Internationally, there is a dearth of research using grounded theory methods with participants from multiple ethnic communities. This paper describes the steps undertaken in developing a cross cultural grounded theory study of Chinese, Indian, and Korean senior immigrants' contribution to New Zealand society. The challenges, learnings, and benefits of undertaking such research are explored and recommendations put forth for developing the use of a grounded theory methodology in cross cultural studies.
\end{abstract}

KEYWORDS: Community Participation, Cross Cultural Research, Immigrants, Grounded Theory, Older Adults.

Immigration is a global phenomenon, as people of all ages and ethnicities choose to relocate and build lives in new, and perhaps, unfamiliar environments. How people settle into their new surroundings and maintain their health and wellbeing is influenced, in part, by the degree to which they are able to engage in activities within their homes and local communities. The nexus of older adults as immigrants, resettlement, and health is a burgeoning focus of research internationally (United Nations, 2016). This article describes the application of a grounded theory methodology in conducting a cross cultural study to explore the active contributions older Chinese, Indian, and Korean immigrants make to New Zealand society as they settle in an environment vastly different to the one which they have been born into and grown up in. The purpose of the paper is to consider the methodological challenges and benefits of using grounded theory methodology in a cross-cultural context. Specific findings from the study have been published elsewhere (Nayar \& Wright-St Clair, 2018; Wright-St Clair \& Nayar, 2016; Wright-St Clair et al., 2018).

Cross cultural studies seek to understand variations in human behavior across two or more cultures as influenced by a cultural context. The intention of the research approach is to consider whether or not behaviors from one culture hold for people from another culture (Matsumoto \& Juang, 2003). Multi-ethnic research may include several cultural groups but,

\footnotetext{
${ }^{1}$ Corresponding author; snayar19@gmail.com
} 
unlike cross cultural studies, not set out to compare behaviors across groups. The behaviors explored in this grounded theory study centered on how older Asian-Chinese, Indian and Korean-immigrants' contribute to community through everyday activities. As a methodology, grounded theory is particularly helpful for uncovering processes or patterns of behavior that remain hidden in society. While New Zealanders are aware of the growing numbers of older Asian immigrants residing in the country (Zodgekar, 2005), due to physical appearances, it may be argued that the everyday activities of this population and their contributions to New Zealand society are less visible and, therefore, less well understood.

As a qualitative methodology, grounded theory is continually evolving. Well known grounded theorist, Kathy Charmaz (2014a), has argued that methodologists have a responsibility to "explicate the national and cultural underpinnings of his or her method" (p. 1082). The next section briefly overviews the history of Asian immigrants to New Zealand before considering the literature on grounded theory and cross cultural studies.

\section{New Zealand's Asian Immigrant Communities}

The Organisation for Economic Co-operation and Development (OECD, 2016) data reveal that in 2013 New Zealand ranked third highest for foreign born population $(28.2 \%$ of total population), behind Switzerland (28.3\%) and Luxembourg (43.7\%). Included in New Zealand's foreign-born population are older adults from the Asian region who are granted approval to join non-dependent adult children previously settled in the country under the Parent Category family reunion policy. Reasons for migration include assisting adult children by caring for the home and grandchildren, seeking support as they transition into advanced age, and seeking a better quality of life in later years (Zhang, 2014). Figures taken from the 2018 census reveal that people identifying as being part of the Asian ethnic group comprise $15.1 \%$ of New Zealand's population; within which, Chinese, Indian, Filipino, and Korean comprise the top four Asian ancestries (Stats NZ, 2019). Asian immigrants constitute the second largest immigrant population in New Zealand; however, theirs has not been an easy journey.

The Chinese Immigrants Restriction Act of 1881 and the Asiatic Restriction Act of 1896 were an attempt by the government of the time to ease local fears about the increasing number of Asians, particularly Chinese gold miners, who were among the first nonPolynesian, non-European immigrants to come to New Zealand (O'Connor, 1990). Excluded from these Acts were immigrants from the Indian sub-continent. As India was part of the British Empire, Indian peoples were entitled to immigrate to New Zealand and were supposed to receive better treatment than immigrants from other Asian nations. To resolve this issue, the New Zealand government introduced the 1899 Immigration Restriction Act. Under this Act, immigrants seeking entry to New Zealand, who were not of British or Irish parentage, were obligated to fill in an application form in 'any European language', which in practice meant English (Beaglehole, 2008; Hutching, 2004; McKinnon, 1996).

The result of these ethnically exclusive policies was that at the end of World War II, Europeans "comprised 93.57 percent of the total population, indigenous Maori accounted for 5.8 percent, and the remaining 0.63 percent were 'race aliens' (mainly Chinese, Indians and Pacific Islanders)" (Brooking \& Rabel, 1995, p. 36). It was not until the 1990s that there was a significant influx in New Zealand's immigrant population from China, Hong Kong, and North-East Asian countries such as Korea and Japan. Reasons for migration included seeking education and employment opportunities, and the attraction of a less crowded environment in which to establish their families (Phillips, 2007).

At the time of the New Zealand 2013 census, 1,614 Chinese, 648 Indian, and 30 Korean immigrants self-identified as having been resettled in New Zealand less than a year; comprising approximately $70 \%$ of immigrants aged 60 years or more who took part in the 
census (Statistics New Zealand, 2013). Given this ethnic diversity, and the goal to uncover how older Asian immigrants participate in New Zealand society, a grounded theory methodology was chosen. Grounded theory is considered useful for exploring and understanding social processes that occur within society (Nayar, 2012; Strauss, 1987); examining various theories in different fields, and allows for deeper interpretations of intercultural experiences to emerge (Sheridan \& Storch, 2009).

\section{Grounded Theory and Cross Cultural Studies}

To date, qualitative methods have been employed in New Zealand research with older Asian immigrants; however, such research has tended to involve only one ethnic group per study (Li et al., 2010; Park \& Kim, 2013; Zhang, 2014). The same trend was found with qualitative studies specifically employing a grounded theory methodology (Kim et al., 2015; Nayar, 2015). Both these grounded theory studies explored the process of resettlement for Korean and Indian immigrants in New Zealand respectively. Grounded theory is a qualitative methodology capable of exploring and understanding social processes that occur within society, in such a way that "explanations of phenomena are grounded in reality" (Grant \& Giddings, 2002, p. 14). Locally and internationally, there is a dearth of research using grounded theory methods with participants from multiple ethnic communities.

Qualitative methodologies are increasingly valuable when undertaking cross cultural studies. The nature of qualitative studies demands researchers address in detail the complexity of the context within such the study is being undertaken. Methodologically, qualitative studies offer the opportunity to consider local and particular experiences, while also reporting relationships and explanatory constructs at a more global level (de Quadros Rigoni, 2016). Further, qualitative methods require researchers to engage with participants over a prolonged period of time, and thereby obtain rich data related to local processes and context (Kvale, 1996). This is particularly important when conducting research with immigrants who, as a vulnerable population, may be hesitant to speak with researchers who are not part of their community (Carling et al., 2014). However, as de Quadros Rigoni (2016) has noted, the benefits and challenges of designing and implementing qualitative cross cultural studies remain under discussed.

In undertaking cross cultural research, Blackman (1983) noted that grounded theory approaches would enable both the development of theory through a systematic manner, and the charting of researcher experiences and perspectives resulting from intercultural contact. Thus, undertaking a cross cultural grounded theory study is a multidimensional and interactive process. However, unlike ethnography, which specifically acknowledges 'culture' as a concept to be studied; grounded theory does "not identify culture as the single most important variable to be analysed" (Barnes, 1996, p. 430). Rather it is the social process that is central to the study. Yet, this social process unfolds within a context, which means that culture cannot be ignored.

Similarly, Kim's (1989) research of immigrant communities argued that an integrative approach of an array of disciplinary approaches, including psychological and sociological, was needed so that the "whole may enable us to offer comprehensive descriptions and explanations of the adaptation process-what happens to individuals as they strive to carry out their life activities in an unfamiliar sociocultural milieu" (p. 103). However, Barnes (1996) has noted that unless culture is made explicit in the use of qualitative methods, "culture can become transparent, lost in the pages of observations, interviews and analyses of social processes" (p. 430). In other words, participants' ethnicity and culture ought to be taken account of throughout the research process.

The cultural foundations of grounded theory have remained implicit (Charmaz, 2014a). Indeed, Clarke (2008) has noted that differences of race and ethnicity, and culture are 
erased in the generalizing of grounded theory methods of analysis. In Barnes' (1996) earlier review of grounded theory and culture, she noted that there were few references to race in the grounded theory literature, aside from earlier remarks by Glaser (1998) in which he noted that variables such as gender and race should not be assumed as having any relevance. Rather, they have to "earn their way into the theory" (Barnes, 1996, p. 434). Thus, it could be argued that it would be possible to conduct a grounded theory analysis of older Korean, Chinese, and Indian immigrants' contributions to society without needing to attend to the construction of ethnicity and race. However, to do so may result in a theory that does not capture or acknowledge the complexity of the participants' process.

Grounded theory allows for the "exploration of interrelatedness of the process of cross-cultural adaptation, which is individual for each migrant" in that it is an "open and flexible approach that is focused on the migrant's actual experiences" (Sheridan \& Storch, 2009 , p. 4). This study, therefore, set out to develop a grounded theory study that revealed the social process of older Asian immigrants contributing to New Zealand. Furthermore, it set out to champion the unique ethnic and cultural values, differences and commonalities as Korean, Chinese, and Indian peoples.

\section{Participants}

Ethical approval for this study was granted by the Auckland University of Technology Ethics Committee [number 12/100].

Using purposive sampling, older immigrants living in Auckland, New Zealand who self-identified as Chinese, Indian, or Korean and meeting the following criteria, were invited to participate: 1) immigrated to New Zealand aged 55 years or older; 2) aged 60 years or older at the time of the study; 3) resident in New Zealand at least 6 months. While the first author had connections with the Indian community, neither author had links with the Chinese or Korean community. Therefore, to ensure participants' needs were valued and accommodated throughout the research process, meetings with community leaders and participation in culturally-bound community events, such as attendance at the Indian Independence Day festivities, took place over a 2 month period. This period of time was critical for a) enabling the researchers to share information about the study and answer questions from prospective participants; and b) building relationships with each of the communities and participants.

All consent forms and participant information sheets were translated into the relevant language (Mandarin, Hindi, Korean) for recruitment. Seventy-six participants were recruited; 24 Chinese, 27 Indian, and 25 Korean. Participants ranged in age from 60 to 83 years and had been resident in New Zealand between 1 and 19 years. The majority of participants were living with a spouse or adult children.

\section{Implementation of a Grounded Theory Cross Cultural Methodology}

Revealing the social process of how older Korean, Chinese, and Indian immigrants contribute to community resulted in a theory that was developed over three phases. The first phase (5 months) saw the development of culture specific theories for each of the three populations; phase two (4 months) focused on cross cultural analysis and the development of a substantive theory that was reflective of all participants. The third, and final, phase (6 weeks) involved taking the theory back to participants for testing, clarification, and finalizing. The steps involved in each of these phases have been summarized in Table 1.

\section{Phase I: Development of Three Culture Specific Theories}


"Cross-cultural analysis should begin with structured observations of phenomena in diverse cultures" (Gales, 2003, p. 132). In the first phase, aligning with Gale's (2003) contention of the need for structured observations, a series of nine focus groups, three with each ethnic community-one female, one male and one mixed gender group-were undertaken to develop an understanding of the social process, community contribution, as it unfolded for each cultural group.

\section{Table 1}

Implementation of the Grounded Theory Cross Cultural Pathway

\begin{tabular}{|c|c|}
\hline Phase & Methods \\
\hline $\begin{array}{l}\text { Phase 1: Development of three } \\
\text { culture specific theories }\end{array}$ & $\begin{array}{l}\text { - Purposive sampling - } 76 \text { participants } \\
\text { - Focus groups - } 9 \\
\text { - Observations } \\
\text { - Theoretical questioning } \\
\text { - Memoing } \\
\text { - Constant comparative analysis - within each of } \\
\text { - the culture specific data sets } \\
\text { - Dimensional matrix }-3\end{array}$ \\
\hline $\begin{array}{l}\text { Phase 2: Development of a cross } \\
\text { cultural substantive theory }\end{array}$ & $\begin{array}{l}\text { - Theoretical sampling }-15 \text { participants } \\
\text { - Individual interviews }-15 \\
\text { - Observations } \\
\text { - Theoretical questioning } \\
\text { - Memoing } \\
\text { - Constant comparative analysis - across } 3 \text { culture } \\
\text { - } \text { specific theories and individual interview data } \\
\text { Dimensional matrix }-1\end{array}$ \\
\hline $\begin{array}{l}\text { Phase 3: Testing, clarifying, and } \\
\text { finalizing the theory }\end{array}$ & $\begin{array}{l}\text { - Member checking } \\
\text { 1) Community leaders } \\
\text { 2) Participants - individually and collectively }\end{array}$ \\
\hline
\end{tabular}

The focus groups were held in community settings and were conducted in Mandarin for the Chinese seniors, Korean for the Korean seniors, and English and/or Hindi for the Indian seniors. Native speaking bilingual research assistants and leaders from each community were present to lead or assist with group facilitation and translations, supported by the authors. Focus group discussions centered on the question "tell us about how you participate in community?" with prompts to facilitate dialogue such as "what has helped with or stopped you from participating?" All discussions lasted between 90 and 120 minutes, and were digitally audio-recorded and transcribed verbatim. Non-English focus groups were then translated into English for the purpose of analysis.

As per grounded theory methods, data collection and analysis occurred concurrently for both phases one and two. Participants were given the option of attending a gender specific or mixed gender focus group. The gender specific focus groups were conducted first for all three communities. The rationale for doing so was to explore what differences/similarities existed between older men and women's participation. Participants in the gender specific focus groups were asked the same questions, and despite being gender specific it was noted that women made comments regarding men's participation and the other way around. These comments were supported in the respective groups, thus adding to the validity and reliability of the focus group method. Observations were written into memos for further analysis. 
Memos are theoretical notes, a unique and complex research tool that provides a crucial link between data collection and theory generation (Glaser, 2004; Lempert, 2007). Memos were written by the authors following each of the focus groups and then discussed to determine if any further areas of enquiry should be explored in the next focus group. The following is an example of a memo written after the Indian male focus group:

\begin{abstract}
This group had a very different focus. The topic of wanting to contribute to community but not being able to was the key issue. The men were all very well educated and skilled and want to be able to use their knowledge and experience to contribute to their communities. They believe that New Zealand has treated/looked after them well and they have an obligation/duty to give something back. However, giving back is more than the 'little' things they do such as looking after grandchildren, passing on traditions, recycling etc. They want to work, have a job, voluntary is fine - there is no need for payment but it must be a job which utilises their knowledge. It seems that the men actually do a lot to contribute to their community but their perception is the value of that contribution is less if not classified as 'employment'.
\end{abstract}

Transcribed data and memoed observations were initially analyzed line by line to identify concepts or codes. Labels given to sentences or phrases captured the meaning of the phenomenon and became codes that described concepts originating from words or phrases in the data (Strauss \& Corbin, 1998). Fundamental to grounded theory is the need for a tightly organised structure; that is, each concept and category should be connected to the other categories. Without the connections, there is the risk of data simply becoming a "string of processes" rather than an integrated whole.

\title{
Table 2
}

Categories and Sub-categories for Korean Participants

Core Process: Working to Repay New Zealand

\begin{tabular}{ll} 
Category & Sub-category \\
\hline Developing self & Mental health \\
& Physical health \\
Supporting communities & New Zealand environment \\
& International aide \\
& New Zealand communities \\
& Korean communities/family \\
Passing on knowledge & Grandchildren (culture) \\
& Teaching skills \\
Wanting to do more & Having connection
\end{tabular}

Conditions

Communication

Resources Time

Place

People

\begin{tabular}{lll}
\hline Strategies & $\begin{array}{l}\text { Uniting minds } \\
\text { Exchanging information }\end{array}$ & $\begin{array}{l}\text { Sharing knowledge } \\
\text { Learning from others }\end{array}$ \\
& Creating environments & \\
\hline Consequences & Living a beautiful life & \\
\hline
\end{tabular}


Having healthy mind and body

Feeling lonely

Following analysis of the gender specific focus groups, the emerging concepts were then taken back to the mixed gender focus group where theoretical questioning was used to tease out particular categories or concepts and further develop the theory for the specific community. For example, within the Korean data, the women's focus group revealed that they often worked together to contribute to their community such as hosting knitting or cooking groups; alternatively, Korean men appeared to work more individually in their community contributions, for instance offering one to one computer lessons. This observation was then taken back to the mixed gender group for a discussion on why this might be the case and how older men and women worked together towards community contribution.

In analyzing the data, the dimensional matrix, developed by Schatzman (1991), provided a framework for the ordering and conceptualizing of data. Using the matrix, the categories and concepts generated from the analysis of the focus groups were organized into three provisional theories (Tables 1, 2, and 3), one for each ethnic community.

Table 3

Categories and Sub-categories for Indian Participants

Core Process: Fulfilling one's duty

\begin{tabular}{ll} 
Category & Sub-category \\
\hline Assisting family & $\begin{array}{l}\text { Easing burden of children } \\
\text { Educating grandchildren } \\
\text { Indian community }\end{array}$ \\
Supporting community & $\begin{array}{l}\text { Wider New Zealand society } \\
\text { Not having opportunities } \\
\text { Openness to opportunities }\end{array}$
\end{tabular}

Conditions

Family needs

Age of grandchildren

Living arrangements

Physical Health and Abilities

Pronunciation

Being Resourced

Skills and systems

People and place

Time

Organizations

\begin{tabular}{lll}
\hline Strategies & $\begin{array}{l}\text { Seeking opportunities } \\
\text { Drawing on strengths } \\
\text { Developing routines }\end{array}$ & \\
\hline Consequences & Passing time gainfully & Mental satisfaction \\
& Developing community & $\begin{array}{l}\text { Friends } \\
\text { Family }\end{array}$ \\
& Increasing local knowledge/ & \\
& understanding & \\
\hline
\end{tabular}

Constant comparative analysis begins when commencing coding and, due to concurrent data collection and analysis, continues with the aim of making comparisons of data at each stage of analysis to find similarities and differences (Charmaz, 2014b). It involves comparing "incident to incident, incident to codes, codes to codes, codes to categories, and categories to categories until a grounded theory is fully integrated" (Birks \& Mills, 2015, p. 11). Utilizing methods of constant comparative analysis across the three theories revealed similar concepts. For instance, the notion of wanting to repay community through supporting 
or assisting with community initiatives and contributing as a means of enhancing individual health and wellbeing came through strongly in each of the individual theories. Given the similarities, the authors deemed that there was enough likeness in concepts across the three theories to warrant pursuing the development of one theory that accounted for the behaviors across all three ethnic groups. This led into the second phase of the study.

Table 4

Categories and Sub-categories for Chinese Participants

\begin{tabular}{ll}
\hline Core Process: Journeying with one's heart & \\
\hline Category & Sub-category \\
\cline { 2 - 3 } Developing self & Mental health \\
& Physical health \\
Paying back society & Sense of duty \\
Assisting community & Supporting family \\
& Chinese community \\
Wanting to do more & Educating New Zealand society \\
& Voluntary work New Zealand \\
& Mixing with New \\
& seniors \\
& Communicating \\
\hline
\end{tabular}

\begin{tabular}{lll}
\hline Conditions & Communication & \\
& Resources & Time \\
& & $\begin{array}{l}\text { Place } \\
\text { People }\end{array}$ \\
\hline Strategies & Developing routines & \\
& Accessing resources & $\begin{array}{l}\text { Locality } \\
\text { Chinese/New Zealand goods }\end{array}$ \\
& Exchanging information & \\
\hline Consequences & Improving health & $\begin{array}{l}\text { Physical } \\
\text { Mental } \\
\end{array}$ \\
& Developing community & Family \\
\hline
\end{tabular}

\section{Phase II: Development of a Cross Cultural Substantive Theory}

In this second phase, the analytic process moved from examining the individual case to comparing across cases in order to determine consistent patterns or differences (Gales, 2003). Elaborating and refining the developing theory required going back to the field and engaging in a process of theoretical sampling, a hallmark of grounded theory methodology (Charmaz, 2006; Strauss \& Corbin, 1998) which, in conjunction with constant comparative analysis, guided both data collection and analysis. In phase two, 15 semi-structured individual interviews, five within each community, were conducted with participants previously recruited to the focus groups.

These participants were identified as being able to offer specific experiences in relation to the research question and emergent categories. For example, within Asian cultures, caring for grandchildren is a task commonly undertaken by grandparents - denoted in the current study's theory under the category 'Caring for Family'. Yet, many older Asian immigrants are choosing to live away from their family (Selvarajah, 2004). Therefore, an Indian gentleman who had chosen to live independently from his family was selected for further interview as part of the theoretical sampling to elaborate on how he participates in 
Caring for Family while not part of the immediate household. Examples of questions asked in individual interviews included: "Some participants commented that they would like to be doing certain activities but are not doing them. What activities would you like to do and what possibly stops you from engaging in such activities?" and, "How do you find out about options for community activities that you might be able to participate in?"

While the focus group interviews were conducted within community settings, the importance of not stripping context from observations was acknowledged through ensuring that interviews for Chinese and Indian participants were conducted at their homes. Interestingly, Korean participants chose a community center or a room at the university. Interviews were conducted in a language of the participant's choice, audio-recorded with consent, and transcribed verbatim and translated into English where necessary.

Analysis of individual interviews occurred alongside the remaining data collection. At this point, the data were coded and constant comparative analysis between the individual interview data and the focus group data was conducted to refine the concepts and categories across the three emergent, ethnic-specific theories. Analysis aimed to develop one cross cultural dimensional matrix that captured the participation aspects and processes for all participants across the provisional theories (Berry, 1989). For example, all participants spoke about the multiple ways in which they cared for their family and thereby contributed to community. Some looked after their grandchildren and were involved in sharing their culture within their grandchildren's school; others assumed the role of cooking within the household thus freeing up their children to go to work and pay taxes. Caring for Family was thus more than what happened within the four walls of the house, it was considered a fundamental part of how older Asian immigrants contribute to New Zealand community. In this way the developing theory (see Figure 1) sought to encompass a cross cultural understanding, grounded in the behaviors arising from the three different ethnic communities.

\section{Figure 1}

Dimensional Matrix of Final Theory 


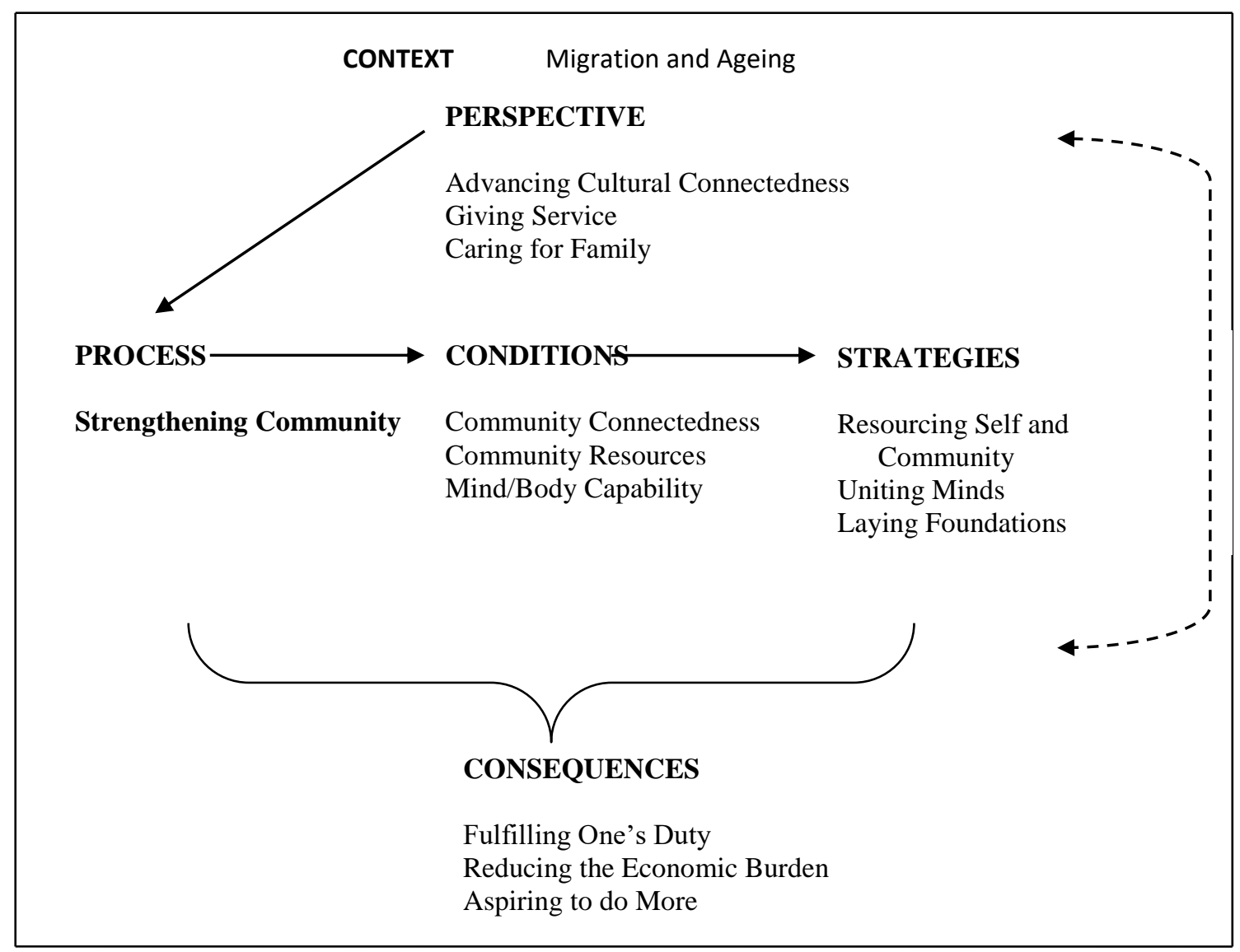

Phase III: Testing, Clarifying and Finalizing the Theory

As the final substantive theory emerged, concepts were taken back to the communities for member checking. At a first level, the final theory was shown to community leaders to gain a macro perspective as to whether the theory was reflective of each of the communities. The diagram as presented in Figure 1 was shown to leaders and a discussion on each of the concepts and the overall process occurred. At this stage each of the leaders acknowledged that they were able to locate their community within the theory that captured the behaviors of all three ethnic groups and had no questions about the theory overall.

Next, the researchers presented the theory to participants, either in the individual interviews or at community gatherings, for verification and development. This process was pivotal for ensuring that the findings were grounded in the experiences of the participants. Across all three cultural groups, participants responded positively to the theory and expressed their desire to meet with participants from the other communities to share their experiences and develop more cross cultural collaborations in their community contributions.

\section{Reflections and Recommendations}

In both qualitative research and grounded theory studies pertaining to migration, issues of positionality and reflexivity have assumed importance (Ganga \& Scott, 2006). In this section we offer our reflections on the process of undertaking a cross cultural research study and recommendations based on our learnings for future grounded theory studies that may be considering including participant groups who come from different ethnic cultural backgrounds. 


\section{Use of Language}

Charmaz (2014a) claimed that “...grounded theorists have given scant attention to how the structure and content of specific languages can affect inquiry" (p. 1078) and Sheridan and Storch (2009) argued that within intercultural research, language becomes an issue when interviews are conducted in a language that is not the interviewees' mother tongue. English is the primary language of both authors, although the second author has limited understanding of some Indian languages. As such, it was important to recruit research assistants who were capable of speaking at least two languages: English and Hindi, Mandarin, or Korean to assist with interviews and translation of data. Professional translators were not used as the research assistants were all experienced with the requirements of translating for research purposes. Further, not all transcripts were back translated. Rather, pertinent quotes from data were back translated and checked by community leaders. It has been argued by some researchers that using an interpreter may result in meanings being lost in translation or muted (Charmaz, 2014a); however, we are emphatic in our decision to use interpreters. Without having employed research assistants who were familiar with the purpose of the study and were willing to engage in multiple conversations regarding language, we could not have completed the study.

Access to the field and analyzing the data in this study was not a quick process. Both required time and a willingness to learn language and cultural context with which we were not previously familiar. It has been recognized that language - words, explanations-differ across and within cultures according to the shared understandings held by members of that culture (Barnes, 1996; Ozfidan \& Mitchell, 2020; Steeves, 1992). This issue was certainly encountered in undertaking a cross cultural study of this nature. In advancing the theory, the category 'Fulfilling One's Duty' was developed. The word duty can hold different connotations. For the second author, in the context of her work on the University ethics committee, duty reflected holding deep moral obligations toward others. However, for the first author, being of Indian origin, the word duty fit very comfortably with notions of dharma and working towards giving back; whereas the word obligation did not resonate with her worldview. For instance, she described looking after her parents in older age as a duty, something that she would choose to do but is not obliged to do. Thus, ensued a lengthy discussion as each explained their position and went back to the data to see in what context the word 'duty' was used. Such discussions were critical for ensuring that the concepts within the theory accurately reflected not just one but all three ethnic groups. After all, "Language is central. Language shapes meanings, fosters forming different types of meanings, and clarifies or conceals connections between meanings and actions" (Charmaz, 2014a, p. 1078).

\section{Collection and Analysis of Data}

Within grounded theory, and qualitative research more broadly, it is necessary that data collection strategies align to the culture and qualities of the research participants (Charmaz, 2014a). Prior to beginning data collection, multiple meetings took place with community leaders and research assistants to ensure that, as the researchers, we understood the needs of each community and what would need to be implemented to make participants feel as ease. For example, even though we were keen to interview individual participants within their homes to gain a better understanding of their living situations and how this may facilitate or hinder community contribution, we respected that the Korean participants felt more comfortable being interviewed within community settings.

Barnes (1996) contended that "adequate analysis of cultural others can only take place when the nonverbal as well as verbal communication is accounted for" (p. 433). During predata collection meetings with community leaders it was observed within the Chinese 
community that the men congregated in one building to play table tennis, while the women participated in line dancing in another building. Recognizing this gender divide, organizing gender specific as well as a mixed gender focus group was a way of giving participants the opportunity to choose which setting felt more comfortable for them to share information. Taking time to meet with community leaders and engaging in activities with community members was an important process for facilitating acceptance within the communities and the gathering of rich data (Charmaz, 2014a; Yusoff, 2019). Thus, all invitations to cultural community events such as the Indian Independence Day celebrations were accepted. Ultimately, investing time beyond that required for gathering data (such as planned interviews and observations) is recommended as critical for undertaking a cross cultural study and needs to be factored in when planning time lines and budget for a study.

Given the lack of literature, or even grounded theory texts, reporting grounded theory studies involving multiple ethnic groups as participants, the design and development of the current study was emergent. The research design was preordained, yet the process was fluid and responsive to circumstances encountered. It was decided that initially using focus groups rather than individual interviews would be of most benefit for constructing the individual theories and determining whether there was any merit in proceeding further to developing one integrated cross cultural theory. While the focus groups yielded rich data and allowed for theoretical questioning, it did mean that potential participants, such as those who are more socially isolated, were not involved. While this may be a limitation of the current theory, it does not negate the potential that lies in developing a grounded theory cross cultural study beyond those populations described in the current paper.

\section{Conclusion}

Grounded theory is a powerful methodology that can change research relationships when used across cultures and societies (Charmaz, 2014a). Undertaking this research was at times challenging but overall an enriching learning experience for both the research team and participants. Morse (2009) posited that grounded theory approaches are continually facing change and Charmaz (2014a) has stated that "international researchers can adopt grounded theory strategies and adapt them to fit their cultural and research practices" (p. 1082). We would argue that it is not a question of 'can'; rather that researchers 'must' adopt and adapt grounded theory strategies to fit within specific cultural contexts. Undertaking this grounded theory study was time and energy intensive and required steep learning, especially when there was little literature to guide how best to proceed with undertaking a cross cultural grounded theory. However, we believe the steps taken, as outlined in this paper, ensured a study that had methodological integrity and which contributes to the body of literature on undertaking grounded theory studies in a cross cultural context. Ultimately, the personal and professional investment has been truly rewarding.

\section{Funding Details}

This research was funded by the Auckland University of Technology Contestable Research Grant [number CGH 26/12].

\section{Acknowledgements}

We thank our research assistants Mr Shimu Wang, Ms Supreet Sodhi, Dr Hagyun Kim; and our community advisors Mr Hu Chongbao, Mr Jeet Suchdev, Mrs Audrey Chung, whose work and expertise in gaining access to the communities and translating data was vital to this research project. 


\section{References}

Barnes, D. M. (1996). An analysis of the grounded theory methods and the concept of culture. Qualitative Health Research, 6(3), 429-441. https://doi.org/10.1177/104973239600600309

Beaglehole, A. (2008). 'Immigration regulation', Te Ara - the Encyclopedia of New Zealand, updated 21-Sep-2007. http://www.TeAra.govt.nz/NewZealanders/NewZealandPeoples/ImmigrationRegulatio $\mathrm{n} / \mathrm{en}$

Berry, J. W. (1989). Imposed etic-emics-derived etics: The operationalization of a compelling idea. International Journal of Psychology, 24, 721-735. https://doi.org/10.1080/00207598908247841

Birks, M., \& Mills, J. (2015). Grounded theory: A practical guide. Sage.

Blackman, B. (1983). Toward a grounded theory. In W. Gudykunst (Ed.), Intercultural communication theory, current perspectives (pp. 283-291). Sage.

Brooking, T., \& Rabel, R. (1995). Neither British nor Polynesian: A brief history of New Zealand's other immigrants. In. S. W. Grief (Ed.), Immigration and national identity in New Zealand (pp. 23-49). The Dunmore Press.

Carling, J., Erdal, M. B., \& Ezzati, R. (2014). Beyond the insider-outsider divide in migration research, Migration Studies, 2(1), 36-54, https://doi.org/10.1093/migration/mnt022

Charmaz, K. (2006). Constructing grounded theory: A practical guide through qualitative analysis. Sage.

Charmaz, K. (2014a). Grounded theory in global perspective: Review by international researchers. Qualitative Inquiry, 20(9), 1074-1084. https://doi.org/10.1177/1077800414545235

Charmaz, K. (2014b). Constructing grounded theory (2nd ed.). Sage.

Clarke, A. E. (2008). Sex/gender and race/ethnicity in the legacy of Anselm Strauss. In N. K. Denzin (Ed.), Studies in symbolic interaction (pp.161-176). Emerald.

de Quadros Rigoni, R. (2016). Benefts and challenges of qualitative methodologies in crosscultural psychology studies. In C. Roland-Lévy, P. Denoux, B. Voyer, P. Boski, \& W. K. Gabrenya Jr. (Eds.), Unity, diversity and culture [Proceedings]. The 22nd Congress of the International Association for Cross-Cultural Psychology. htps://scholarworks.gvsu.edu/iaccp_papers/227

Gales, L. M. (2003). Linguistic sensitivity in cross-cultural organisational research: Positivist/post-positivist and grounded theory approaches. Language \& Intercultural Communication, 3(2), 131-140. https://doi.org/10.1080/14708470308668097

Ganga, D., \& Scott, S. (2006). Cultural "insiders" and the issue of positionality in qualitative migration research: Moving "across" and moving "along" researcher-participant divides. Forum: Qualitative Social Research, 7(3), Art. 7.

Glaser, B. (2004). Remodelling grounded theory. Forum: Qualitative Social Research, 5(2), Art. 4.

Glaser, B. G. (1998). Doing grounded theory: Issues and discussions. Sociology Press.

Grant, B. M., \& Giddings, L. S. (2002). Making sense of methodologies: A paradigm framework for the novice researcher. Contemporary Nurse, 13(1), 10-28. https://doi.org/10.5172/conu.13.1.10

Hutching, M. (2004). Becoming New Zealanders: Population, immigration and citizenship, 1940-1960. http://nzhistory.net.nz/dnzb_exhibs/citizen/

Kim, H., Hocking, C., McKenzie-Green, B., \& Nayar, S. (2015). Occupational experiences of Korean immigrants settling in New Zealand. Journal of Occupational Science, 23(2), 181-195. https://doi.org/10.1080/14427591.2015.1126168 
Kim, Y. Y. (1989). Personal, social and economic adaptation: 1975-1979 arrivals in Illinois. In D. Haines (Ed.), Refugees as immigrants, Cambodians, Laotians and Vietnamese in America (pp. 86-104). Rowman and Littlefield.

Kvale, S. (1996). InterViews: An introduction to qualitative research interviewing. Sage.

Lempert, L. (2007). Asking questions of the data: Memo writing in the grounded thoery tradition. In K. Charmaz, \& A. Bryant (Eds.), The SAGE handbook of grounded theory (pp. 245-264). Sage.

Li, W. W., Hodgetts, D., \& Ho, E. (2010). Gardens, transitions and identity reconstruction among older Chinese immigrants to New Zealand. Journal of Health Psychology, 15(5), 786-796. https://doi.org/10.1177/1359105310368179.

Matsumoto, D., \& Juang, L. (2003). Culture and psychology (3rd ed.). Wadsworth.

McKinnon, M. (1996). Immigrants and citizens: New Zealanders and Asian immigration in historical context. Institute of Policy Studies.

Morse, J. M. (2009). Tussles, tensions and resolutions. In J. M. Morse, P. N. Stern, J. Corbin, B. Bowers, A. E. Clarke, \& K. Charmaz (Eds.), Developing grounded theory (pp. 1322). Left Coast Press.

Nayar, S. (2012). Grounded theory: A research methodology for occupational science. $\begin{array}{llll}\text { Journal of Occupational } & \text { Science, } & \text { 19(1), }\end{array}$ https://doi.org/10.1080/14427591.2011.581626

Nayar, S. (2015). Re-situating models of acculturation: An occupational dimension. Journal of International Migration and Integration, 16(4), 1141-1155. https://doi.org/10.1007/s12134-014-0379-8

Nayar, S., \& Wright-St.Clair, V. (2018). Strengthening community: Senior Asian immigrants contributing to New Zealand society. Journal of Cross-Cultural Gerontology, 33(4), 355-368. https://doi.org/10.1007/s10823-018-9357-5

O’Connor, M. (1990). An immigrant nation. Heinemann Education.

Organisation for Economic Co-operation and Development. (2016). OECD data: Foreign born population. https://data.oecd.org/migration/foreign-bornpopulation.htm\#indicator-chart

Ozfidan, B., \& Mitchell, C. (2020). Detected Difficulties in Argumentative Writing: The Case of Culturally and Linguistically Saudi Backgrounded Students. Journal of Ethnic and Cultural Studies, 7(2), 15-29. http://dx.doi.org/10.29333/ejecs/382

Park, H. J., \& Kim, C. G. (2013). Ageing in an inconvenient paradise: The immigrant experiences of older Korean people in New Zealand. Australasian Journal on Ageing, 32(3), 158-162. https://doi.org/10.1111/j.1741-6612.2012.00642.x.

Phillips, J. (2007). History of immigration. Te Ara - the Encyclopedia of New Zealand. http://www.TeAra.govt.nz/NewZealanders/NewZealandPeoples/HistoryOfImmigratio $\mathrm{n} / \mathrm{en}$

Schatzman, L. (1991) Dimensional analysis: Notes on an alternative approach to the grounding of theory in qualitative research. In D. R. Maines (Ed.), Social organization and social process (pp. 303-314). Aldine De Gruyter.

Selvarajah, C. (2004). Expatriation experiences of Chinese immigrants in New Zealand. Management Research News, 27(8/9), 26-45. https://doi.org/10.1108/01409170410784626

Sheridan, V., \& Storch, K. (2009). Linking the intercultural and grounded theory: Methodological issues in migration research. Forum: Qualitative Social Research, 10(1), Art. 36.

Statistics New Zealand. (2013). 2013 Census of population and dwellings. http://www.stats.govt.nz/searchresults.aspx?q=2013\%20Census\%20of\%20Population $\% 20$ and\%20Dwellings 
Stats NZ. (2019). New Zealand's population reflects growing diversity. https://www.stats.govt.nz/news/new-zealands-population-reflects-growing-diversity

Steeves, R. H. (1992). A typology of data collected in naturalistic interview. Western Journal of Nursing Research, 14(4), 532-536. https://doi.org/10.1177/019394599201400412

Strauss, A. L. (1987) Qualitative analysis for social scientists. Cambridge University Press.

Strauss, A., \& Corbin, J. (1998). Basics of qualitative research: Techniques and procedures for developing grounded theory (2nd ed.). Sage.

United Nations, Department of Economic and Social Affairs, Population Division. (2016). International Migration Report 2015: Highlights (ST/ESA/SER.A/375).

Wright-St Clair, V. A., \& Nayar, S. (2016). Older Asian immigrants' participation as cultural enfranchisement. Journal of Occupational Science, 24(1), 64-75.

Wright-St Clair, V. A., Nayar, S., Kim, H., Wang, S. M., Sodhi, S. K., Chung, A., Suchdev, J., \& Hu, C. (2018). Asian late-life immigrants managing wellness through contributing to socially embedded networks. Journal of Occupational Science, 25(1), 51-64. https://doi.org/10.1080/14427591.2017.1370607

Yusoff, N. (2019). Cultural heritage, Emotion, Acculturation, Ethnic minority, Valence. Journal of Ethnic and Cultural Studies, 6(3), 53-63. http://dx.doi.org/10.29333/ejecs/259

Zhang, J. (2014). Elderly Chinese migrants, intergenerational reciprocity, and quality of life. New Zealand Sociology, 29(2), 11-30.

Zodgekar, A. (2005). The changing face of New Zealand's population and national identity. In J. H. Liu, T. McCreanor, T. McIntoosh, \& T. Teaiwa (Eds.), New Zealand identities: Departures and destinations (pp. 140-154). Victoria University Press.

\section{Notes on Contributors}

Dr. Shoba Nayar originally trained as an occupational therapist and was working at AUT University at the Centre for Migrant and Refugee Research at the time of undertaking this study. She is currently working as an independent academic based in Chennai, India. Her research interests are in the fields of migration and resettlement, mental health, and qualitative methodologies.

Professor Wright-St Clair is Co-director AUT Centre for Active Ageing Research Group. She researches older people's valued activities, community inclusiveness and participation, residential aged care, cross-cultural studies, and occupational science.

Manuscript received September 04, 2020

Final revision received November 26, 30, 2020

Accepted December 01, 2020 